\title{
Impact of Oral Mastication on the in vitro Digestibility of Pigmented and Non-Pigmented Rice Varieties
}

\author{
Sivakamasundari S K ${ }^{1(\mathbb{D})}$, Priyanka $S^{1(\mathbb{D})}$, Moses J A ${ }^{1(\mathbb{D})}$, Anandharamakrishnan $\mathrm{C}^{1, *(\mathbb{D})}$ \\ 1 Computational Modeling and Nanoscale Processing Unit, Indian Institute of Food Processing Technology (IIFPT), Ministry of \\ Food Processing Industries, Government of India, Thanjavur, Tamil Nadu-613005, India \\ * Correspondence: anandharamakrishnan@iifpt.edu.in (A.C.);
}

Scopus Author ID 16548780200

Received: 3.03.2021; Revised: 10.04.2021; Accepted: 14.04.2021; Published: 26.04.2021

\begin{abstract}
The extent of starch hydrolysis and glycemic index (GI) of foods depends on how it is orally processed, but many in vitro digestion studies failed to consider the oral phase of digestion. This research aimed to understand the relationship between oral mastication and GI of rice. For this study, different rice varieties (pigmented and non-pigmented) were selected and analyzed for their physicochemical properties. The amylose content for all rice varieties was higher than $25 \%$, with the starch content of $68.68 \pm 0.70 \%$ $81.60 \pm 1.78 \%$. Temporal dominance of sensation was determined for rice samples to understand the consumers' sensory preferences towards the pigmented rice varieties. In vivo oral mastication studies were also performed for the rice varieties, in which significant differences were observed amongst pigmented and non-pigmented rice samples. The particle size for pigmented rice varieties after in vivo oral mastication was significantly larger (50\% particles greater than $2 \mathrm{~mm}$; due to its intact morphology) than non-pigmented rice. The significant impact of oral processing on the GI of rice irrespective of the varieties was also observed in this study. Thus, this research sheds light on the need for oral processing for in vitro digestion studies.
\end{abstract}

Keywords: In vivo oral processing; Rice; Mastication and bolus properties; Temporal dominance of sensations; In vitro glycemic index.

(C) 2021 by the authors. This article is an open-access article distributed under the terms and conditions of the Creative Commons Attribution (CC BY) license (https://creativecommons.org/licenses/by/4.0/).

\section{Introduction}

During the initial phase of digestion (oral stage), the ingested food is broken down into small particles through biting and mastication, and it is simultaneously mixed with saliva to form a swallowable bolus which further undergoes gastric digestion [1]. Also, during mastication, the ingested food's surface area increases as it is fragmented into smaller particles whose average particle size is usually less than $2 \mathrm{~mm}$; thus, the surface area available for gastric digestion increases. The $\alpha$-amylase enzyme present in saliva aids in breaking starch molecules into subsequent sugars molecules during oral processing [1]. Moreover, it was reported by various researchers that oral digestion contributes to $50 \%$ hydrolysis of starch for selected food products $[2]$.

The southern part of India cultivates some pigmented rice varieties, which include red rice and black rice, and they are found to be a good source of nutrients, polyphenols, and micronutrients 
[3]. Red rice is rich in iron and zinc, while black rice is rich in crude fiber and protein. Ramiah and Rao [4] stated that the level of zinc and iron in red rice is higher than that of white rice. Besides, these rice varieties are rich in antioxidants that aid in preventing allergies, inflammations, and cancer; they are also recognized to play a prominent role in weight loss and weight management. The major bioactive compound responsible for the color in the pigmented rice is anthocyanin [5]. Apart from that, Vichapong et al. [6] observed the presence of various phenolic compounds in the pigmented rice. Thus, in recent times the consumption of minimally processed rice, brown rice, and other pigmented rice varieties are highly recommended since they are rich in micronutrients, fiber, polyphenols, and proteins; and also because they have significantly lower GI compared to their highly refined counterpart's [3].

Oral processing of cooked rice undergoes various complex processes such as mechanical destruction, biochemical and enzymatic interaction [7], thus influencing the glucose response but, there has been no comprehensive research on the oral processing of pigmented rice varieties. Therefore, in this research, we aimed to identify in vivo oral mastication and bolus characteristics of pigmented and non-pigmented rice varieties. Furthermore, the influence of oral processing on the GI of rice varieties was determined, as most in vitro studies ignored the oral processing stage of products like cooked rice [2]. To understand the consumer preference for the pigmented rice varieties, a new sensory protocol (temporal dominance of sensation) was also used in this research.

\section{Materials and Methods}

\subsection{Sample selection.}

In the present study, pigmented and non-pigmented rice varieties, namely kothamali samba (A), navara (B), kudaivazhai (C), karungkuruvai (D), poongar (E), and seeraga samba (F) (Figure 1) were selected and procured from Thanjavur, India. All the samples except $F$ were pigmented rice varieties. The samples were further stored in airtight pouches at $4{ }^{\circ} \mathrm{C}$ for further experiments, and analytical-grade chemicals were used throughout the study.

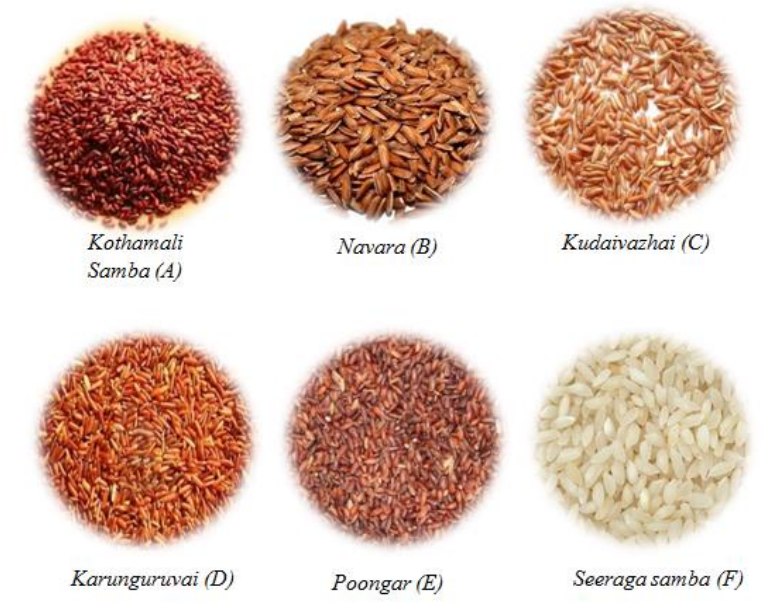

Figure 1. Selected rice samples for the mastication study.

\subsection{Physicochemical properties of rice.}

The rice samples were analyzed for various physicochemical properties such as length, breadth, thickness, 1/b ratio, 1000 kernel weight, bulk density, volume, sphericity, moisture content 
(\%wb), amylose, and starch content with reference to Sivakamsundari et al. [8]. The color value of rice grains was calculated using a Hunter color lab (Color flex EZ) [9], and calibration of the equipment was performed using standard black and white tile.

\subsection{Pasting property of rice.}

Rice grains were ground in a mixer and sieved $(2 \mathrm{~mm})$ to achieve uniform particle size, and it was ensured that the samples' moisture content was $12 \%$. Then $3 \mathrm{~g}$ rice flour was added into the sample cup of rheometer (Modular Compact Rheometer MCR52, Anton Paar, Austria), to which $25 \mathrm{~g}$ of distilled water was added, and its pasting properties were determined [10].

\subsection{Total phenol, flavonoid, and antioxidant property of rice.}

\subsubsection{Sample preparation.}

The rice grains were powdered, and about $10 \mathrm{~g}$ of samples were mixed with acidified methanol for extraction in a reciprocating shaker at $30{ }^{\circ} \mathrm{C}$, and after $24 \mathrm{~h}$, centrifugation of the extract was done $(1000 \times \mathrm{g}, 15 \mathrm{~min})$ to obtain a clear supernatant (extract) for further analysis [11].

\subsubsection{Total phenolic content of rice.}

The phenolic content of the extracted sample was determined using the procedure given by Preeti et al. [9] with some modifications. Briefly, $100 \mu \mathrm{l}$ of extract, $1 \mathrm{ml}$ of Folin-Ciocalteu reagent were mixed thoroughly, to which $1 \mathrm{ml}$ sodium carbonate (10\%) was added and using distilled water, the final volume of the samples was made to $5 \mathrm{ml}$. The samples were then incubated for 2 $\mathrm{h}$ at room temperature, and the absorbance was recorded. For determining total phenols in the extracted sample, gallic acid (GRM233, Hi-Media, Mumbai) was used as the standard. The results are expressed in gallic acid equivalent (GAE/100g) of the samples.

\subsubsection{Total flavonoid content of rice.}

As explained by Liu and Yao [12], the total flavonoid content of rice was determined. Briefly, $100 \mu \mathrm{l}$ of the sample were added with sodium nitrite $(5 \%, 75 \mu \mathrm{l}$, retained at room temperature for $6 \mathrm{~min})$ and aluminum chloride $(10 \%, 150 \mu \mathrm{l}$, stored at room temperature for 5 min). Finally, $0.5 \mathrm{ml}$ of $1 \mathrm{M}$ sodium hydroxide was added to the samples, vortexes, and recorded absorbance. For determining total flavonoids in the extracted sample, quercetin (RM6191, HiMedia, Mumbai) was used as the standard.2.4.4. Radical scavenging activity of rice.

The DPPH (2,2- Diphenyl-1-picryl hydrazyl) assay was used to determine the rice samples' radical scavenging activity. The assay was performed using the method explained by Sivakamasundari et al. [13].

\subsection{In vivo oral processing of rice.}

2.5.1. Selection of participants for in vivo oral processing of rice.

For this study, ten human volunteers were selected ( 5 male; 5 female) of age $24 \pm 10$ years, and informed written consent was taken from them before the study. The personal information 
about the volunteers would be protected. Pre-screening of the subjects for dental conditions was performed and apart from that, they were enquired about their allergies to food and other medical conditions. The experiments were conducted for the volunteers individually to prevent the effect of influence.

2.5.2. Temporal dominance of sensation for rice (TDS analysis).

The TDS is a recently emerged method that describes different types of sensory perceptions during every bite of food (from the first bite until swallowing). The TDS (texture TDS and flavor TDS) for the rice varieties was determined using the approach explained by Sethupathy et al. [1] with Senso Maker software. Before the analysis, the panel members were explained in detail about the list of attributes provided in the software for conducting TDS, and also, they were trained individually to access the computerized software.

\subsubsection{Experimental design for the in vivo oral processing of rice.}

The experiments were conducted at $11.00 \mathrm{am}$. The volunteers were provided with cooked rice samples (10 g) in a cup, and they were asked to consume the samples using the spoon from which the portion size (Eq.1) of each individual was determined. After obtaining the portion size data, each individual was provided with the fixed amount (Table 3) of samples, and in vivo oral processing study was conducted. Throughout the experiment, the volunteers were carefully monitored and instructed not to swallow the sample, and after completion of mastication, they were asked to expectorate the bolus samples in a clean petri-dish.

\section{Portion size $=$ Initial weight of cooked rice in the sample cup - Final weight of rice bolus in the sample cup Eq. (1)}

\subsubsection{Determination of oral processing parameters.}

Mastication features like chew cycles and consumption time were keenly monitored during the oral processing. Further, other mastication properties like chew cycle duration Eq.(2), chewing rate Eq.(3), and eating rate Eq.(4) were calculated using the method explained by van Eck et al. [14]. The expectorated bolus samples were then used to determine solid loss (bolus property) Eq. (5) as given by van Eck et al. [14].

$$
\begin{aligned}
& \text { Chew cycle duration }(s)=\frac{\text { Food consumption time }(s)}{\text { Number of chews }} \quad \text { Eq. (2) } \\
& \text { Chewing rate }\left(\frac{\text { Chews }}{s}\right)=\frac{\text { Number of chews }}{\text { Food consumption time (s) }} \quad \text { Eq. (3) } \\
& \text { Eating rate }\left(\frac{g}{s}\right)=\frac{\text { Weight of food consumed }}{\text { Food consumption time }(s)} \\
& \text { Solid loss during mastication (\%) }=\frac{\text { Weight of food-weight of bolus }}{\text { Weight of food }} \text { Eq. (5) }
\end{aligned}
$$


2.5.5. Particle size analysis of the oral masticated samples.

The particle size distribution of rice varieties after oral processing was measured using sieve analysis as explained by Peyron et al. [15]. The masticated samples collected from the volunteers were cleaned with tap water over the sieve to remove the adhering saliva, and the mass retained on the sieve apertures of $\mathrm{S} 1-2 \mathrm{~mm}, \mathrm{~S} 2-1 \mathrm{~mm}, \mathrm{~S} 3-0.50 \mathrm{~mm}$ were calculated for particle size.

\subsection{In vitro digestion and GI determination of masticated samples.}

The in vitro GI of the masticated rice was measured using the approach explained by Sethupathy et al. [1], and Eq. (6) and Eq. (7) were used to determine starch hydrolysis parameters [16].

$$
\begin{array}{ll}
H I=\frac{\text { Area under the curve of sample }}{\text { Area under the curve of reference sample (glucose) }} & \text { Eq. (6) } \\
G I=39.71+(0.549 * H I) & \text { Eq. (7) }
\end{array}
$$

\subsection{Statistical analysis.}

Statistical analyses for the rice samples were performed using SPSS software (Ver.20.0) at the significance level $p<0.05$. Correlation between the oral processing parameters of the rice varieties was determined using Microsoft Office Excel 2007.

\section{Results and Discussion}

\subsection{Physical and cooking properties of rice.}

Table 1 represents the physical and cooking properties of rice samples. For all the rice varieties except for $\mathrm{C}$, the length was less than $5.5 \mathrm{~mm}$ (small grain type), whereas, for rice variety, $\mathrm{C}$ length was $5.83 \mathrm{~mm}$ (medium grain type) [17].

\begin{tabular}{|c|c|c|c|c|c|c|}
\hline Parameters & $\mathbf{A}$ & B & $\mathbf{C}$ & D & $\mathbf{E}$ & $\mathbf{F}$ \\
\hline Length (mm) & $4.80 \pm 0.17^{\mathrm{a}}$ & $5.40 \pm 0.10^{\mathrm{b}}$ & $5.83 \pm 0.15^{\mathrm{b}}$ & $5.27 \pm 0.25^{\mathrm{bc}}$ & $5.30 \pm 0.20^{\mathrm{bc}}$ & $4.90 \pm 0.10^{\mathrm{a}}$ \\
\hline Breadth (mm) & $2.27 \pm 0.25^{\mathrm{a}}$ & $2.33 \pm 0.06^{\mathrm{a}}$ & $2.50 \pm 0.26^{\mathrm{a}}$ & $2.32 \pm 0.03^{\mathrm{a}}$ & $2.23 \pm 0.06^{\mathrm{a}}$ & $1.60 \pm 0.10^{b}$ \\
\hline Thickness (mm) & $2.10 \pm 0.20^{\mathrm{a}}$ & $1.93 \pm 0.15^{\mathrm{a}}$ & $2.17 \pm 0.06^{\mathrm{a}}$ & $2.20 \pm 0.10^{\mathrm{a}}$ & $2.17 \pm 0.12^{\mathrm{a}}$ & $1.33 \pm 0.15^{\mathrm{b}}$ \\
\hline Length: width & $1.69 \pm 0.14^{\mathrm{a}}$ & $2.32 \pm 0.10^{\mathrm{b}}$ & $2.35 \pm 0.18^{\mathrm{b}}$ & $2.29 \pm 0.13^{\mathrm{b}}$ & $2.37 \pm 0.05^{\mathrm{b}}$ & $2.44 \pm 0.14^{\mathrm{b}}$ \\
\hline Volume $\left(\mathrm{mm}^{3}\right)$ & $9.58 \pm 2.35^{\mathrm{a}}$ & $12.74 \pm 0.87^{\mathrm{ab}}$ & $16.53 \pm 1.74^{\mathrm{cb}}$ & $14.10 \pm 1.16^{\mathrm{cb}}$ & $13.46 \pm 1.55^{\mathrm{abc}}$ & $4.36 \pm 0.60^{\mathrm{d}}$ \\
\hline Surface area $(\mathrm{m}$ & $34.15 \pm 8.35^{\mathrm{a}}$ & $34.87 \pm 1.42^{\mathrm{a}}$ & $40.41 \pm 7.95^{\mathrm{a}}$ & $34.43 \pm 0.34^{\mathrm{a}}$ & $32.14 \pm 1.74^{\mathrm{a}}$ & $16.66 \pm 1.83^{\mathrm{b}}$ \\
\hline Sphericity (\%) & $69.00 \pm 3.27^{\mathrm{a}}$ & $53.67 \pm 1.86^{\mathrm{b}}$ & $54.14 \pm 54.14^{\mathrm{b}}$ & $56.93 \pm 1.18^{b}$ & $55.64 \pm 0.75^{\mathrm{b}}$ & $51.92 \pm 2.95^{\mathrm{b}}$ \\
\hline 1000 kernels weight (g) & $24.36 \pm 0.77^{\mathrm{a}}$ & $32.98 \pm 2.19^{\mathrm{b}}$ & $35.08 \pm 2.27^{b}$ & $36.07 \pm 1.27^{b}$ & $36.67 \pm 0.99^{\mathrm{b}}$ & $14.50 \pm 0.56^{\mathrm{c}}$ \\
\hline Bulk density $\left(\mathrm{kg} / \mathrm{m}^{3}\right)$ & $815.51 \pm 15.16^{\mathrm{a}}$ & $797.70 \pm 0.01^{\mathrm{a}}$ & $801.67 \pm 13.14^{\mathrm{a}}$ & $805.75 \pm 10.97^{\mathrm{a}}$ & $803.15 \pm 9.02^{\mathrm{a}}$ & $824.69 \pm 6.05^{\mathrm{a}}$ \\
\hline Effective diameter & $10.16 \pm 1.12^{\mathrm{a}}$ & $14.20 \pm 0.26^{\mathrm{b}}$ & $16.30 \pm 0.91^{\mathrm{b}}$ & $14.41 \pm 1.16^{\mathrm{b}}$ & $14.24 \pm 0.88^{\mathrm{b}}$ & $7.99 \pm 0.39^{\mathrm{a}}$ \\
\hline MC (\%wb) & $10.17 \pm 0.06^{\mathrm{a}}$ & $9.93 \pm 0.23^{\mathrm{a}}$ & $10.33 \pm 0.15^{\mathrm{a}}$ & $10.13 \pm 0.21^{\mathrm{a}}$ & $10.20 \pm 0.10^{\mathrm{a}}$ & $10.20 \pm 0.10^{\mathrm{a}}$ \\
\hline Cooking time (min) & $37.67 \pm 2.52^{\mathrm{a}}$ & $36.33 \pm 3.79^{a}$ & $37.67 \pm 3.79^{\mathrm{a}}$ & $37.90 \pm 1.35^{\mathrm{a}}$ & $36.00 \pm 2.00^{\mathrm{a}}$ & $27.67 \pm 2.52^{b}$ \\
\hline Total starch (\%) & $73.94 \pm 0.85^{\mathrm{a}}$ & $70.32 \pm 0.62^{\mathrm{a}}$ & $79.13 \pm 3.44^{\mathrm{a}}$ & $68.68 \pm 0.70^{\mathrm{a}}$ & $79.28 \pm 0.46^{\mathrm{a}}$ & $81.60 \pm 1.78^{a}$ \\
\hline Amylose content (\%) & $26.25 \pm 1.31^{\mathrm{a}}$ & $26.27 \pm 0.19^{\mathrm{a}}$ & $26.52 \pm 0.30^{\mathrm{a}}$ & $26.07 \pm 0.20^{\mathrm{a}}$ & $31.90 \pm 0.70^{\mathrm{b}}$ & $26.72 \pm 1.13^{\mathrm{a}}$ \\
\hline
\end{tabular}

Table 1. Physical properties of rice varieties.

Different alphabets in the rows' superscript indicate a statistically significant difference (at $p<0.05$ ) between the 
Similar to length, rice variety $\mathrm{C}$ had a higher breadth, surface area, and effective diameter. Further, the 1000 kernel weight was higher for rice variety E $(36.67 \pm 0.99 \mathrm{~g})$. In terms of bulk density, rice variety $\mathrm{F}$ displayed a higher value $\left(824.69 \pm 6.05 \mathrm{~kg} / \mathrm{m}^{3}\right)$. Sphericity was higher for rice variety $\mathrm{A},(69.00 \pm 3.27 \%)$. Further, the moisture content of all the rice varieties ranged between 9.93 - 10.33 (\% wet basis (wb)) (Statistically insignificant, p>0.05). Cooking time for variety $F$ was lesser $(27.67 \pm 2.52 \mathrm{~min})$, with significant differences $(\mathrm{p}<0.05)$.

\subsection{Total starch and amylose content of rice.}

Table 1 represents the total starch and amylose content of rice. The rice variety $\mathrm{F}$ had higher starch $(81.60 \pm 1.78 \%)$ and the amylose content of variety E was higher $(31.90 \pm 0.70 \%)$. Apart from that, all the samples had amylose content greater than $25 \%$. Thus, it was classified to be higher amylose rice varieties [18]. Meera et al. [19] reported similar inferences for pigmented rice varieties.

\subsection{The color value of rice.}

The color value of rice grains is represented in Figure 2. Among the samples, variety $F$ (non-pigmented rice) had a higher " $L$ " (Lightness) value (61.03) with significant differences $(\mathrm{p}<0.05)$ followed by variety C (30.57), B (28.72), E (26.01), A (25.88) and D (25.85). All the pigmented rice varieties showed positive and higher " $a$ " (redness) value as they had an external red-pigmented layer [20]. The " $b "$ (yellowness) value for the rice varieties was in agreement with the " $L$ " value, which was higher for non-pigmented rice, followed by the pigmented rice varieties and Reddy et al. [11] reported similar inferences. Also, grain color variations in rice directly indicate the existence of different phenolic and flavonoid compounds which aids in preventing disease conditions such as type II diabetes, obesity, etc. [21].

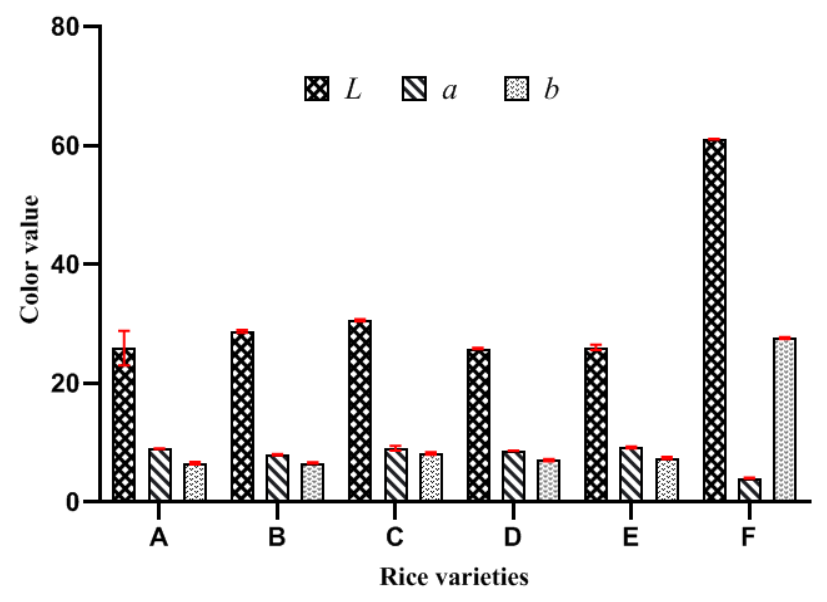

Figure 2. The color value of rice.

\subsection{Pasting property of rice.}

One of the essential parameters in formulating new products using rice flour on an industrial scale is its pasting property [22]. Figure 3 and Table 2 show that the pasting properties of rice variety $\mathrm{F}$ were higher than the other samples, which may be due to the formation of the amylose-lipid or amylose-protein complex [23]. 
Higher peak viscosity for F explains its ability to bind with water through hydrogen bonds [24], whereas higher breakdown viscosity indicates its resistance to shear during stirring [25]. Thus, rice varieties with a lower breakdown viscosity are more thermally stable to heat and shear [26]. The set back viscosity of rice flour indicates the degree of re-crystallization of rice flour during the cooling stage of the experiment [27]. The pasting temperature of rice flour varied between 50.01 and $53.54{ }^{\circ} \mathrm{C}$, with no major variations $(\mathrm{p}>0.05)$ between the varieties.

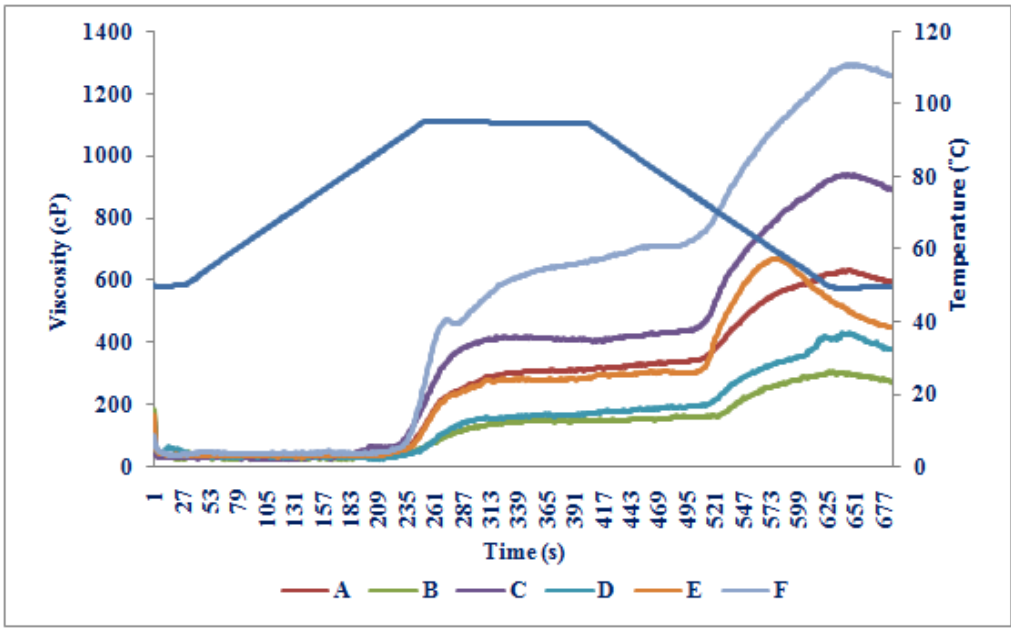

Figure 3. Pasting property of rice flour.

\begin{tabular}{|c|c|c|c|c|c|}
\hline $\begin{array}{c}\text { Rice } \\
\text { variety }\end{array}$ & $\begin{array}{c}\text { PT (Pasting } \\
\text { temperature, }{ }^{\circ} \mathrm{C} \text { ) }\end{array}$ & $\begin{array}{c}\text { PV (Peak } \\
\text { viscosity, cP) }\end{array}$ & $\begin{array}{l}\text { SB (Set back } \\
\text { viscosity, cP) }\end{array}$ & $\begin{array}{c}\text { Final viscosity, } \\
\text { (cP) }\end{array}$ & $\begin{array}{c}\text { BD }(\text { Breakdown } \\
\text { viscosity, cP) }\end{array}$ \\
\hline $\mathrm{A}$ & $50.28^{\mathrm{a}}$ & $125.75^{\mathrm{a}}$ & $464.55^{\mathrm{a}}$ & $514.60^{\mathrm{a}}$ & $75.63^{a}$ \\
\hline B & $50.14^{\mathrm{a}}$ & $62.65^{\mathrm{a}}$ & $240.90^{b}$ & $277.35^{b}$ & $26.26^{\mathrm{a}}$ \\
\hline $\mathrm{C}$ & $50.04^{\mathrm{a}}$ & $162.35^{\mathrm{bc}}$ & $719.55^{\mathrm{c}}$ & $787.90^{c}$ & $94.98^{\mathrm{a}}$ \\
\hline $\mathrm{D}$ & $53.54^{\mathrm{a}}$ & $61.06^{\mathrm{a}}$ & $343.10^{\mathrm{ab}}$ & $376.70^{\mathrm{ab}}$ & $27.46^{\mathrm{a}}$ \\
\hline$E$ & $50.48^{\mathrm{a}}$ & $112.90^{\mathrm{ac}}$ & $405.20^{\mathrm{a}}$ & $448.60^{\mathrm{a}}$ & $69.46^{\mathrm{a}}$ \\
\hline $\mathrm{F}$ & $50.11^{\mathrm{a}}$ & $240.40^{b}$ & $1204.00^{\mathrm{d}}$ & $1260.50^{\mathrm{d}}$ & $184.10^{b}$ \\
\hline
\end{tabular}

Different alphabets in the columns' superscript indicate a statistically significant difference (at $\mathrm{p}<0.05)$ between the varieties.

\subsection{Total phenol, flavonoid, and antioxidant property of rice.}

The antioxidant property of pigmented and non-pigmented rice varieties are given in Figure 4. Total phenols in rice samples ranged from 119.49 to $585.65 \mathrm{mg} \mathrm{GAE} / 100 \mathrm{~g}$ with no significant differences at $\mathrm{p}>0.05$, and a lower phenolic content was observed for non-pigmented rice $(F)$. The flavonoid content for pigmented rice was also higher than non-pigmented rice, ranging from 31.56 to $97.78 \mathrm{mg} / 100 \mathrm{~g}$ for the extract. It has higher levels of polyphenolic compounds flavonoids, anthocyanin, and phenolic acids [28]. Also, the antioxidant potential was higher for variety A, followed by B, D, E, C, and F. Thus, the radical scavenging activity was significantly different $(\mathrm{p}<0.05)$ amongst the pigmented and non-pigmented rice varieties. The findings were also in consistent with the color value of rice (Figure 2), where the higher value of " $a$ " corresponds to the higher antioxidant potential. Thus, consumption of pigmented rice might increase the intake of various bioactive compounds with various functional properties. 


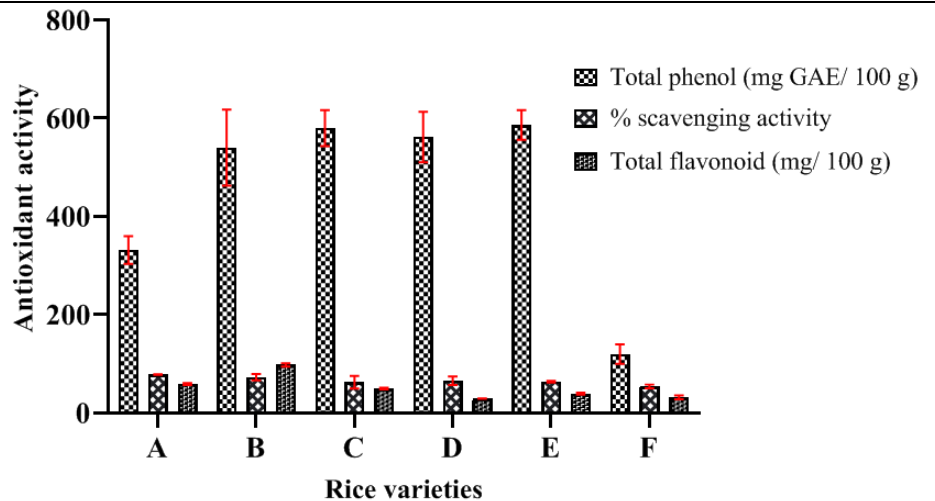

Figure 4. Antioxidant property of rice.


Figure 5. (a) F-TDS and T-TDS for rice (A-F reprersents the rice varieties); (b) Maximum dominance rate of sensory perceptions (A-F reprersents the rice varieties). 


\subsection{Temporal dominance of sensation (TDS) for rice.}

The temporal dominance profile of rice was analyzed in terms of both flavor-TDS (F-TDS) and texture-TDS (T-TDS) and the results are represented in Figure $5 \mathrm{a}$ and $\mathrm{D}_{\max }$ (maximum dominance rate) of different parameters is given in Figure 5b. The F-TDS of pigmented rice varieties displayed branny flavor above the significant level due to the presence of various phenolic compounds on the external pericarp layer [29] and earthy flavor above the chance level due to the presence of 2-Isobutyl-3-methoxypyrazine [30]. However, for the non-pigmented rice F, a starchy flavor was dominant. Besides, the variety $\mathrm{F}$ also exhibited aromatic flavor, and it was significantly higher than the other samples due to the presence of compounds like $\beta$-sitosterol, diisooctyl ester, geranyl-linallol, squalene, and 1,2-benzenedicarboxylic acid [31]. Apart from that, all the rice varieties were reported to have starchy flavor above the chance level during in vivo oral mastication.

In the case of T-TDS, the dominance rate for hardness was higher for the pigmented rice (A and B) during the initial stage of mastication, i.e., 0 - $10 \mathrm{~s}$, whereas, for variety $\mathrm{D}$, chewiness and adhesiveness were dominant, followed by pastiness and grainy. Also, the sensation of grainy was above the chance level for all the rice varieties. On the contrary, the variety $\mathrm{F}$ had the dominant sensation of firmness, adhesiveness, and pastiness. This behavior is clearly due to an external pericarp layer of pigmented rice varieties which is responsible for higher hardness and decreased adhesiveness. Similar results were observed by Wu et al. [32] from the texture profile analysis of white and brown rice.

\subsection{In vivo oral processing properties of rice.}

The in vivo oral mastication and bolus properties of the rice varieties are given in Table 3. The portion size for the pigmented rice varieties was significantly lesser $(\mathrm{p}<0.05)$, which may result in a lower intake of food than the non-pigmented rice F. Conversely, the chew cycles, consumption time and chew cycle duration was significantly $(p<0.05)$ lesser for $F$ but with higher eating rate and solid loss than the pigmented rice as it has an outer pericarp layer. Thus, pigmented rice was consumed less in quantity and required higher consumption time than the non-pigmented rice F [33]. Similar observations were reported by Moongngarm et al. [34] for the chewing behavior of white and brown rice (with external bran layer). Figure 6 represents the particle size distribution of the rice varieties after in vivo oral processing. For the pigmented rice varieties (A E) almost $50 \%$ of bolus particles were greater than $2 \mathrm{~mm}$, whereas for variety $\mathrm{F}$ only $32.51 \%$ of bolus particles were greater than $2 \mathrm{~mm}$, and $50.90 \%$ of bolus particles were greater than $1 \mathrm{~mm}$. Thus during oral mastication, white rice was chewed easily due to its softness, while the intact morphology (presence of bran layer) of pigmented rice prevented the particle breakdown during chewing. Also, in this study inverse relationship between portion size and particle size was observed.

Further, the Pearson correlation analysis was performed to determine the relationship between mastication parameters during rice consumption. The portion size of rice during in vivo oral processing was highly correlated with eating rate $\left(\mathrm{R}^{2}-0.92\right)$ and solid loss $\left(\mathrm{R}^{2}-0.94\right)$ (i.e., higher the portion size, higher the eating rate, and solid loss for variety F). On the other hand, the 
chew cycles during mastication were highly correlated with consumption time $\left(\mathrm{R}^{2}-0.78\right)$ (for pigmented rice varieties).

Table 3. In vivo oral mastication parameters of rice.

\begin{tabular}{c|c|c|c|c|c|c} 
Parameters & $\mathbf{A}$ & $\mathbf{B}$ & $\mathbf{C}$ & $\mathbf{D}$ & $\mathbf{E}$ & $\mathbf{F}$ \\
\hline Potion size (g) & $7.61 \pm 1.37^{\mathrm{a}}$ & $7.32 \pm 1.09^{\mathrm{a}}$ & $7.27 \pm 1.08^{\mathrm{a}}$ & $8.06 \pm 1.19^{\mathrm{a}}$ & $8.06 \pm 0.69^{\mathrm{a}}$ & $10.07 \pm 1.06^{\mathrm{b}}$ \\
\hline Chew cycles (No's) & $30.83 \pm 2.64^{\mathrm{a}}$ & $33.83 \pm 3.13^{\mathrm{a}}$ & $32.83 \pm 4.71^{\mathrm{a}}$ & $35.50 \pm 3.62^{\mathrm{a}}$ & $36.83 \pm 3.43^{\mathrm{a}}$ & $25.83 \pm 2.48^{\mathrm{b}}$ \\
\hline Consumption time (s) & $27.83 \pm 2.7^{\mathrm{a}}$ & $30.33 \pm 3.27^{\mathrm{a}}$ & $27.17 \pm 1.72^{\mathrm{a}}$ & $30.33 \pm 4.68^{\mathrm{a}}$ & $26.83 \pm 3.06^{\mathrm{a}}$ & $21.00 \pm 3.03^{\mathrm{b}}$ \\
\hline Chewing cycle duration (s) & $0.91 \pm 0.10^{\mathrm{a}}$ & $0.90 \pm 0.14^{\mathrm{a}}$ & $0.85 \pm 0.15^{\mathrm{a}}$ & $0.86 \pm 0.11^{\mathrm{a}}$ & $0.74 \pm 0.13^{\mathrm{a}}$ & $0.81 \pm 0.10^{\mathrm{a}}$ \\
\hline Chewing rate (chews/s) & $1.11 \pm 0.12^{\mathrm{a}}$ & $1.13 \pm 0.17^{\mathrm{a}}$ & $1.22 \pm 0.22^{\mathrm{a}}$ & $1.19 \pm 0.17^{\mathrm{a}}$ & $1.39 \pm 0.24^{\mathrm{a}}$ & $1.24 \pm 0.15^{\mathrm{a}}$ \\
\hline Eating rate (g/s) & $0.25 \pm 0.05^{\mathrm{a}}$ & $0.22 \pm 0.05^{\mathrm{a}}$ & $0.23 \pm 0.06^{\mathrm{a}}$ & $0.23 \pm 0.05^{\mathrm{a}}$ & $0.22 \pm 0.04^{\mathrm{a}}$ & $0.39 \pm 0.05^{\mathrm{b}}$ \\
\hline
\end{tabular}
varieties.

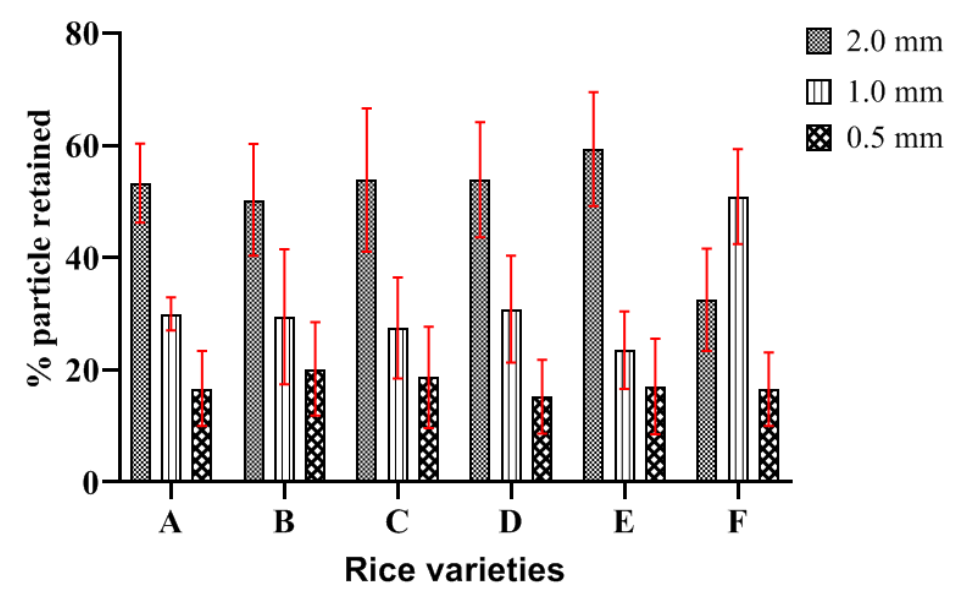

Figure 6. Particle size distribution of in vivo masticated rice.

\subsection{In vitro digestion and GI determination of masticated samples.}

The starch digestibility parameters for the rice varieties were determined and presented in Table 4, from which the correlation between in vivo oral mastication parameters and GI was calculated. From the results, it can be observed that GI was positively associated with portion size $\left(R^{2}-0.66\right)$, eating rate $\left(R^{2}-0.65\right)$, and solid loss $\left(R^{2}-0.56\right)$ in which higher GI was found in variety $\mathrm{F}$ with higher portion size and eating rate. Besides, it was found that rice's GI was negatively associated with chew cycles $\left(\mathrm{R}^{2}-(-0.54)\right)$, consumption time $\left(\mathrm{R}^{2}-(-0.26)\right)$, and chewing rate $\left(\mathrm{R}^{2}\right.$ $-(-0.36))$. Thus, the results indicated that oral processing of foods greatly impacts its GI and further digestion and absorption.

Further, the starch hydrolysis parameters for the rice varieties were determined by fitting the rate of starch hydrolysis (\%) with a first-order reaction [35], and it was observed that the equilibrium \% hydrolyzed starch $\left(\mathrm{C}_{\infty}\right)$ was higher for non-pigmented rice $\mathrm{F}$. On the other hand, for the pigmented rice varieties, the starch hydrolysis rate $\left(\mathrm{k}, \mathrm{min}^{-1}\right)$ was lower than that of nonpigmented rice, which showed that more starch was hydrolyzed in the case of $\mathrm{F}$ when compared to other pigmented rice samples.

Furthermore, rice varieties were classified based on their GI, with varieties D and F having higher GI values than other varieties (statistically significant $\mathrm{p}<0.05$ ), most likely due to differences in starch digestibility and physicochemical characteristics. Also, a strong positive 
correlation was observed between $\mathrm{C}_{\infty}$ and GI $\left(\mathrm{R}^{2}=0.99\right)$, and thus, variety $\mathrm{F}$ with higher $\mathrm{C}_{\infty}$ had higher GI. In pigmented rice varieties, phenolic compounds might have contributed to its reduced GI, as observed from Figure 4. Similar observations in the GI values for pigmented rice varieties were reported by Meera et al. [19]. Thus, the consumption of pigmented rice could help in reducing the risk of type II diabetes.

Table 4. Starchy hydrolysis and glycemic index of the oral masticated sample.

\begin{tabular}{c|c|c|c|c|c} 
Rice varieties & $\mathbf{C}_{\infty}(\boldsymbol{\%})$ & $\mathbf{k}\left(\mathbf{m i n}^{-\mathbf{1}}\right)$ & $\mathbf{H I}$ & $\mathbf{G I}$ & $\mathbf{R}^{\mathbf{2}}$ \\
\hline A & $47.87 \pm 1.74^{\mathrm{ad}}$ & $0.09 \pm 0.01^{\mathrm{a}}$ & $44.90 \pm 3.09^{\mathrm{a}}$ & $64.36 \pm 1.70^{\mathrm{a}}$ & 0.98 \\
\hline $\mathrm{B}$ & $51.91 \pm 1.06^{\mathrm{a}}$ & $0.08 \pm 0.01^{\mathrm{a}}$ & $47.75 \pm 2.59^{\mathrm{ab}}$ & $65.93 \pm 1.42^{\mathrm{ab}}$ & 0.97 \\
\hline $\mathrm{C}$ & $41.65 \pm 1.56^{\mathrm{bd}}$ & $0.08 \pm 0.005^{\mathrm{a}}$ & $38.84 \pm 3.05^{\mathrm{ac}}$ & $61.03 \pm 1.68^{\mathrm{ac}}$ & 0.99 \\
\hline $\mathrm{D}$ & $52.17 \pm 2.91^{\mathrm{ac}}$ & $0.09 \pm 0.01^{\mathrm{a}}$ & $48.76 \pm 0.48^{\mathrm{ab}}$ & $66.48 \pm 1.06^{\mathrm{ab}}$ & 0.99 \\
\hline E & $44.58 \pm 0.94^{\mathrm{d}}$ & $0.07 \pm 0.01^{\mathrm{a}}$ & $40.75 \pm 1.93^{\mathrm{ac}}$ & $62.08 \pm 1.06^{\mathrm{ac}}$ & 0.96 \\
\hline F & $56.95 \pm 1.67^{\mathrm{c}}$ & $0.07 \pm 0.02^{\mathrm{a}}$ & $52.21 \pm 2.56^{\mathrm{b}}$ & $68.37 \pm 1.40^{\mathrm{b}}$ & 0.98
\end{tabular}

$\mathrm{C} \infty$ - Equilibrium (\%) of hydrolyzed starch; $\mathrm{k}$ - starchy hydrolysis rate $\left(\mathrm{min}^{-1}\right) ; \mathrm{HI}$ - Hydrolysis index; GI -

Glycemic index. Different alphabets in the columns' superscript indicate a statistically significant difference (at $\mathrm{p}<0$

$.05)$ between the varieties.

\section{Conclusions}

In vivo oral processing was performed for the rice varieties, and it showed substantial variances amongst the different rice varieties. In pigmented rice varieties, the presence of an intact pericarp layer resulted in higher chewing duration and consumption time with decreased particle breakdown during oral processing. The TDS analysis confirmed the presence of branny and earthy flavor due to the pericarp layer in the pigmented rice. The GI of rice was determined, with pigmented rice varieties having a medium GI due to the presence of various phenolic compounds, as evidenced by antioxidant activity, while non-pigmented rice varieties had a higher GI. Also, the current study results strongly highlight the importance of the oral processing step in the digestion process. Thus, it is crucial for foods with such composition to consider the oral processing step while performing in vitro digestion experiments. Also, the current research is an eye-opener that displays the importance of forgotten and underutilized pigmented rice varieties which are the treasure house of micronutrients and antioxidants.

\section{Funding}

The first author acknowledged the funding from the Department of Science and Technology (DST), Govt. of India through INSPIRE, Ph.D. fellowship (Grant No: IF180587).

\section{Acknowledgments}

This research has no acknowledgment.

\section{Conflicts of Interest}

The authors declare no conflicts of interest.

\section{References}

1. Sethupathy, P.; Sivakamasundari, S.K.; Moses, J.A.; Anandharamakrishnan, C. Effect of varietal differences on https://biointerfaceresearch.com/ 
https://doi.org/10.33263/BRIAC121.11481160

the oral processing behavior and bolus properties of cooked rice. Int. J. Food Eng. 2020, https://doi.org/10.1515/ijfe-2020-0097.

2. Tamura, M.; Okazaki, Y.; Kumagai, C.; Ogawa, Y. The importance of an oral digestion step in evaluating simulated in vitro digestibility of starch from cooked rice grain. Food Res. Int. 2017, 94, 6-12, https://doi.org/10.1016/j.foodres.2017.01.019.

3. Priya, T.S.R.; Nelson, A.R.L.E.; Ravichandran, K.; Antony, U. Nutritional and functional properties of coloured rice varieties of South India: a review. J. Ethn. Foods. 2019, 6, 11, https://doi.org/10.1186/s42779-019-0017-3.

4. Ramiah, K.; Rao, M. Rice Breeding and Genetics, ICAR. New Delhi, Monogr. 1953, 19.

5. Hiemori, M.; Koh, E.; Mitchell, A.E. Influence of cooking on anthocyanins in black rice (Oryza sativa L. japonica var. SBR). J. Agric. Food Chem. 2009, 57, 1908-1914, https://doi.org/10.1021/jf803153z.

6. Vichapong, J.; Sookserm, M.; Srijesdaruk, V.; Swatsitang, P.; Srijaranai, S. High performance liquid chromatographic analysis of phenolic compounds and their antioxidant activities in rice varieties. LWT-Food Sci. Technol. 2010, 43, 1325-1330, https://doi.org/10.1016/j.lwt.2010.05.007.

7. Sethupathy, P.; Moses, J.A.; Anandharamakrishnan, C. Food Oral Processing and Tribology: Instrumental Approaches and Emerging Applications. Food Rev. Int. 2020, 1-34, https://doi.org/10.1080/87559129.2019.1710749.

8. Sivakamasundari, S.K.; Moses, J.A.; Anandharamakrishnan, C. Effect of parboiling methods on the physicochemical characteristics and glycemic index of rice varieties. J. Food Meas. Charact. 2020, 14, 1-16, https://doi.org/10.1007/s11694-020-00551-9.

9. Preethi, R.; Deotale, S.M.; Moses, J.A.; Anandharamakrishnan, C. Conductive hydro drying of beetroot (Beta vulgaris L) pulp: Insights for natural food colorant applications. J. Food Process Eng. 2020, e13557, https://doi.org/10.1111/jfpe.13557.

10. Anukiruthika, T.; Moses, J.A.; Anandharamakrishnan, C. 3D printing of egg yolk and white with rice flour blends. J. Food Eng. 2020, 265, 109691, https://doi.org/10.1016/j.jfoodeng.2019.109691.

11. Reddy, C.K.; Kimi, L.; Haripriya, S. Variety difference in molecular structure, functional properties, phytochemical content and antioxidant capacity of pigmented rice. J. Food Meas. Charact. 2016, 10, 605-613, https://doi.org/10.1007/s11694-016-9344-x.

12. Liu, Q.; Yao, H. Antioxidant activities of barley seeds extracts. Food Chem. 2007, 102, 732-737, https://doi.org/10.1016/j.foodchem.2006.06.051.

13. Sivakamasundari, S K., Anu Bhushani, J., Maria Leena, M., Moses, J A., Anandharamakrishnan, C. Formulation and characterization of $\beta$ carotene loaded solid lipid nanoparticles. J. Food Process. Preserv. 2019, 43, 1-9, https://doi.org/10.1111/jfpp.14212.

14. van Eck, A.; Hardeman, N.; Karatza, N.; Fogliano, V.; Scholten, E.; Stieger, M. Oral processing behavior and dynamic sensory perception of composite foods: Toppings assist saliva in bolus formation. Food Qual. Prefer. 2019, 71, 497-509, https://doi.org/10.1016/j.foodqual.2018.05.009.

15. Peyron, M.-A.; Mishellany, A.; Woda, A. Particle size distribution of food boluses after mastication of six natural foods. J. Dent. Res. 2004, 83, 578-582, https://doi.org/10.1177/154405910408300713.

16. Santhi Rajkumar, P.; Suriyamoorthy, P.; Moses, J.A.; Anandharamakrishnan, C. Mass transfer approach to invitro glycemic index of different biscuit compositions. J. Food Process Eng. 2020, e13559. https://doi.org/10.1111/jfpe.13559

17. Karpagam, V.; Vinoth, R.; Kalaiyarasi, R. Grain quality characteristics of two line hybrids in rice (Oryza sativa L.). Int. J. Plant Sci. 2016, 11, 207-212, https://doi.org/10.15740/has/ijps/11.2/207-212.

18. Juliano, B. Amylose Analysis in Rice - A Review. Proc. Work. Chem. Asp. Rice Grain Qual. (International Rice Res. Institute). 1979, 251-260.

19. Meera, K.; Smita, M.; Haripriya, S.; Sen, S. Varietal influence on antioxidant properties and glycemic index of pigmented and non-pigmented rice. J. Cereal Sci. 2019, 87, 202-208, https://doi.org/10.1016/j.jcs.2019.03.005.

20. Saikia, S.; Dutta, H.; Saikia, D.; Mahanta, C.L. Quality characterisation and estimation of phytochemicals content and antioxidant capacity of aromatic pigmented and non-pigmented rice varieties. Food Res. Int. 2012, 46, 334340, https://doi.org/10.1016/j.foodres.2011.12.021.

21. Ye, L.; Wang, C.; Wang, S.; Zhou, S.; Liu, X. Thermal and rheological properties of brown flour from Indica rice. J. Cereal Sci. 2016, 70, 270-274, https://doi.org/10.1016/j.jcs.2016.07.007.

22. Champagne, E.T.; Bett, K.L.; Vinyard, B.T.; McClung, A.M.; Barton, F.E.; Moldenhauer, K.; Linscombe, S.; 
McKenzie, K. Correlation between cooked rice texture and rapid visco analyser measurements. Cereal Chem. 1999, 76, 764-771, https://doi.org/10.1094/CCHEM.1999.76.5.764.

23. Pradipta Sandy; Mohammad Ubaidillah; Tri Agus Siswoyo. Physicochemical, Functional and Antioxidant properties of Pigmented Rice. Curr. Res. Nutr. Food Sci. J. 2020, 8, 837-851, https://doi.org/10.12944/CRNFSJ.8.3.15.

24. Otegbayo, B.; Oguniyan, D.; Akinwumi, O. Physicochemical and functional characterization of yam starch for potential industrial applications. Starch-Stärke. 2014, 66, 235-250, https://doi.org/10.1002/star.201300056.

25. Falade, K.O.; Christopher, A.S. Physical, functional, pasting and thermal properties of flours and starches of six Nigerian rice cultivars. Food Hydrocoll. 2015, 44, 478-490, https://doi.org/10.1016/j.foodhyd.2014.10.005.

26. Samyor, D.; Deka, S.C.; Das, A.B. Evaluation of physical, thermal, pasting characteristics and mineral profile of pigmented and nonpigmented rice cultivars. J. Food Process. Preserv. 2016, 40, 174-182, https://doi.org/10.1111/jfpp.12594.

27. Kong, X.; Zhu, P.; Sui, Z.; Bao, J. Physicochemical properties of starches from diverse rice cultivars varying in apparent amylose content and gelatinisation temperature combinations. Food Chem. 2015, 172, 433-440, https://doi.org/10.1016/j.foodchem.2014.09.085.

28. Boue, S.M.; Daigle, K.W.; Chen, M.-H.; Cao, H.; Heiman, M.L. Antidiabetic potential of purple and red rice (Oryza sativa L.) bran extracts. J. Agric. Food Chem. 2016, 64, 5345-5353, https://doi.org/10.1021/acs.jafc.6b01909.

29. Bett-Garber, K.L.; Lea, J.M.; Champagne, E.T.; McClung, A.M. Whole-grain rice flavor associated with assorted bran colors. J. Sens. Stud.2012, 27, 78-86, https://doi.org/10.1111/j.1745-459X.2011.00368.x.

30. Jezussek, M.; Juliano, B.O.; Schieberle, P. Comparison of key aroma compounds in cooked brown rice varieties based on aroma extract dilution analyses. J. Agric. Food Chem. 2002, 50, 1101-1105, https://doi.org/10.1021/jf0108720.

31. Mohan, M.M.; Balakrishnan, A.; Renganayaki, P.R. A high yielding seeragasamba rice culture VG 09006 and its medicinal properties. Electron. J. Plant Breed. 2013, 4, 1148-1154.

32. Wu, J.; Chen, J.; Liu, W.; Liu, C.; Zhong, Y.; Luo, D.; Li, Z.; Guo, X. Effects of aleurone layer on rice cooking: A histological investigation. Food Chem. 2016, 191, 28-35, https://doi.org/10.1016/j.foodchem.2014.11.058.

33. Zijlstra, N.; de Wijk, R.; Mars, M.; Stafleu, A.; de Graaf, C. Effect of bite size and oral processing time of a semisolid food on satiation. Am. J. Clin. Nutr. 2009, 90, 269-275, https://doi.org/10.3945/ajcn.2009.27694.

34. Moongngarm, A.; Bronlund, J.E.; Grigg, N.; Sriwai, N. Chewing behavior and bolus properties as affected by different rice types. Int. J. Med. Biol. Sci. 2012, 6, 51-56.

35. Goñi, I.; Garcia-Alonso, A.; Saura-Calixto, F. A starch hydrolysis procedure to estimate glycemic index. Nutr. Res. 1997, 17, 427-437, https://doi.org/10.1016/S0271-5317(97)00010-9. 